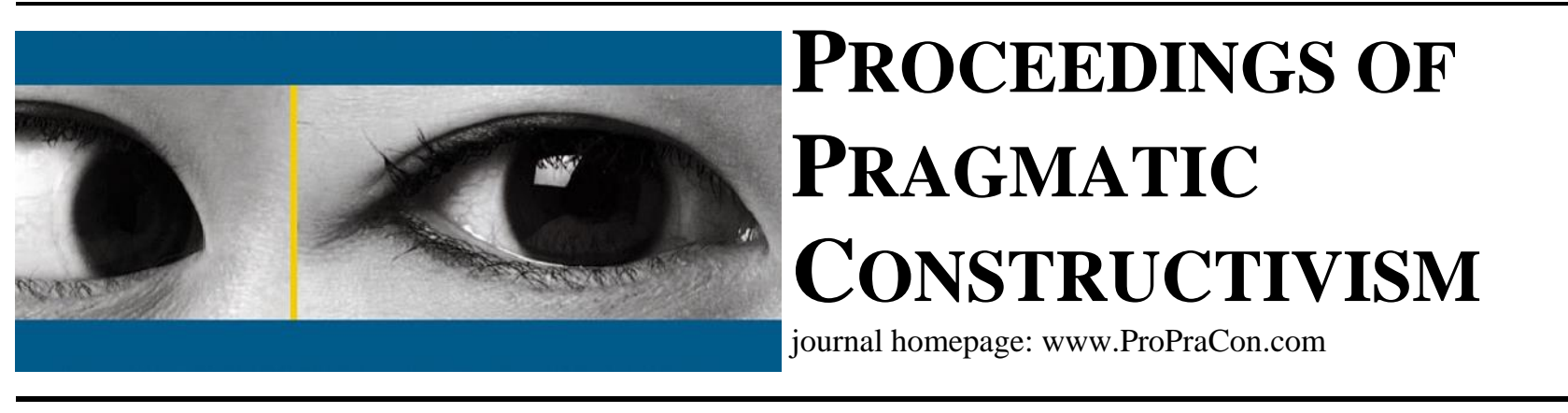

\title{
Conceptualizing concepts - The case of "trust" and “control” seen from a pragmatic constructivist view
}

\author{
Peter Beusch \\ Senior Lecturer in Management Accounting \\ University of Gothenburg; School of Business, Economics and Law \\ Vasagatan, 40530 Göteborg, Sweden; peter.beusch@handels.gu.se
}

Keywords: Trust; control; management control; pragmatic constructivism; concept; conceptualization and problematization.

\section{Purpose}

This article examines concepts of trust and concepts of control particularly found within management accounting research, for itself and together. The most prominent/influential concepts, and the underlying assumptions behind them, are problematized and re-conceptualized in order to generate new research questions.

\section{Methodology}

A theorizing methodology is used, including the analysis and problematization of the content of important concepts, which is grounded in the relevant literature. The pragmatic constructivist approach is applied to structure the findings and relate them to different dimensions of reality.

\section{Findings}

Two distinct research perspectives, hence a realistic/positivistic versus a sociological/constructivist, can be made out in the field of control and trust within management accounting. Particular researchers' use of particular constructs, and the absence of conflicting constructs within the same perspective, demonstrates that reality out there is still mainly described in two different ways. However, both ways ignore some aspects of reality and the world as it is in practice. One interesting finding describes how trust could be seen as a 'package' as well, the same way as we in the field are speaking about 'management control packages' (Malmi \& Brown, 2008).

\section{Originality}

Several new models illustrate the re-conceptualized constructs of trust and control, for itself and together. These models must be further evaluated in order to achieve real validity and can as such, in this paper only be seen as provocative. The aim with this provocation is to generate truly new research questions and this with help of 'thinking outside the box' as this research is not supposed to be 'footnote-on-footnote research' (Alvesson and Sandberg, 2011). 